\title{
Field measurement of contact forces on rollers for a large diameter pipe conveyor
}

https://doi.org/10.1515/eng-2021-0014

Received Sep 09, 2020; accepted Nov 04, 2020

\begin{abstract}
An intensive field measurement was carried out to assess the force acting on the rollers for a large diameter pipe conveyor. A special idler enclosing two dynamometers was designed and installed in the various roller positions. The forces on the rollers were metered while the conveyor was running with and without conveying material. The position of the two dynamometers was such allowing to derive the theoretical contact point of the belt onto the roller. The measurements were carried out in a straight section of the pipe conveyor and in the centre part of a horizontal curve. Obtained data are presented, analysed, and compared with the values from a six-point stiffness testing device. Further, the participation factor of the material load on the roller forces for a single roller is derived. The study concludes with a critical review of the findings comparing them with results presented in the literature.
\end{abstract}

Keywords: Belt roller contact force, Rubber-textile belt, Pipe conveyor, Six-point Stiffness Testing Device, Field measurement

\section{Introduction}

The design engineer of a pipe conveyor needs to take a series of decision establishing the design and characteristic of every single component. The State-of-the-Art knowledge allows the designer to take sound and economically choices for up to medium size pipe conveyors. When it comes to large diameter pipe conveyors, references and or design guidelines become rare or not existing at all. Whereas, most design parameters can be extrapolated, when it comes to the roller design, the engineer is mostly

\footnotetext{
^Corresponding Author: E. Bombasaro: Bedeschi SpA, Via Praimbole 38, 35010 Limena (PD), Italy; Email: emanuel.bombasaro@bedeschi.com

R. Oddera: Bedeschi SpA, Via Praimbole 38, 35010 Limena (PD), Italy; Email: roberto.oddera@bedeschi.com
}

left to its own experience. The lack of standards and guidelines is also expressed in [1] and [2].

Current works [1,3-10] and [11] have studied and collected in dept the behaviour of belt forming forces. However, all the measurements are carried out on test stands and the obtained results are not compared to measurements taken on executed and operational pipe conveyors. The principal aim of the cited studies was to detect abnormal behaviour or as in [12] to assure the belt having suffcient stiffness to not collapse during operation.

[13] and [14] approached the belt forming forces problem with the means of finite element analysis. Unfortunately, both studies again only compare to laboratory experiments.

In contrast [15] and [16] did measurements on an existing pipe conveyor, but unfortunately lacked a direct comparison to estimated values or laboratory experiments.

All above cited works present a deep insight into the behaviour of belt stiffness and associated belt forming forces. Dependencies on belt forming forces were investigated varying belt tension, position and material fill. The studies did those investigations for pipe conveyors with diameters up to $350 \mathrm{~mm}$.

Starting from the existing knowledge presented above, this work wants to contribute with roller load data measured during commissioning on a large diameter pipe conveyor. Those data are compared with experimental results from a six-point stiffness test device. The study is pushed further investigating probabilistic characteristics of the forces on the rollers and with the help of signal identification, the belt behaviour is characterised.

\subsection{System}

The pipe conveyer is part of a coal thermoelectric power plant, conveying the coal from the jetty into the coal storage. The conveyor starts out on the ground in a straight line, then makes a horizontal curve to the right and gains elevation to the coal storage building top. The pipe conveyor system with all its dimension and main technical data are represented in Figure 1. The panel spacing along straight sections of the conveyor is $2.2 \mathrm{~m}$ were as in curved

○ Open Access. (C) 2021 E. Bombasaro and R. Oddera, published by De Gruyter. (cc) $\mathrm{BY}$ This work is licensed under the Creative Commons Attribution 4.0 License 


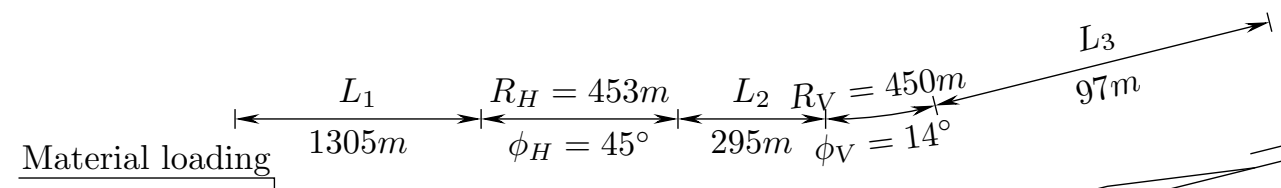

Material loadin

Tail Pulley

Motor $3 r$

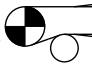

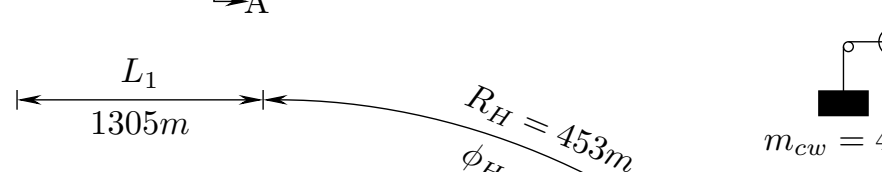

Tail Pulley

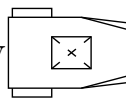

Panel 145

Technical characteristics:

Conveyor capacity

$3000 \mathrm{th}^{-1}$

Volumetric capacity

$1157 \mathrm{~m}^{3} \mathrm{~s}^{-1}$

Fill rate

$70 \%$

Conveyor speed

Material unit mass

$5.0 \mathrm{~ms}^{-1}$

Belt width

Belt thickness

Belt type

Belt unit mass

$166.7 \mathrm{kgm}^{-1}$

$2600 \mathrm{~mm}$

$28 \mathrm{~mm}$

Length between centres $2155 \mathrm{~m}$

Lifting height

$33 \mathrm{~m}$

Overall belt length

$4382 \mathrm{~m}$

Pipe diameter

Overlap

$700 \mathrm{~mm}$

$495 \mathrm{~mm}$

Figure 1: Pipe system in sectional and plan view, including technical characteristics.

sections (vertical and horizontal) the panel spacing is $1.6 \mathrm{~m}$.

\subsection{Definitions}

Throughout the document rollers and panels are identified with numbers. The individual numbers of the rollers are shown in Section A-A in Figure 1.

Roller numbers have been attributed anticlockwise in the running sense of each strand of the conveyor. Panels where numbered on site increasing from the jetty towards the storage building.

The single measurements on the rollers are labelled with following string: id_yyy_rr_tttt_ss_nnnn. Where id is ID number, yyy panel number, $r r$ roller number, tttt belt running condition, $s$ if a stiffener profile was applied to the panel SY(yes) or SN(no) and nnnn additional notes (may be suppressed).

This naming convention is used throughout this document. For example, 01_145_08_all_SN means a measurement with ID 01, taken on panel 145 of roller 08 in all conditions (start, running and stop) without stiffener profile on panel.

During commissioning phase light vibrations on the panels were observed. To mitigate those vibrations a stiffener profile was applied horizontally in the vertical centre of the panel. Aiming to understand, if the vibrations have any influence on the roller loads. Measurement cam- 
paigns were carried out with and without the stiffener profile showing no influence whatsoever.

\section{Laboratory experiments}

The transverse flexibility of the belt is experimented by testing a $150 \mathrm{~mm}$ wide section in a six-point stiffness test device. This test configuration can be considered the minimum and most simple setup to investigate the belt behaviour in terms of forming a pipe and as such is widely used.

For this study two stripes of belt were prepared according to recommendations given in [17]. [10] gives a good summery of validated test rigs. A large variety of more or less complex test stand exist, some even tensioning the belt. Figure 2 shows images of the six-point stiffness test device used for this study. The contact surface properties between the rollers and belt were tried to be as realistic as possible. To achieve this the contact plates were convex in shape and painted. The load cells are U93 cells from HBM. On purpose the experiment was kept simple, as the aim was to understand if valid design parameters can be derived anyway. Results obtained from the contact force experiment are summarised in Table 1 . The contact forces are measured for $5 \mathrm{~min}$ after placing the sample in the sixpoint stiffness test device. The measurement rate was $5 \mathrm{~Hz}$ and the contact forces is the arithmetic mean, Eq. (1), of the final $2 \mathrm{~s}$ of the measured time series. Between the overlap a $0.1 \mathrm{~mm}$ thick PTFE Film was placed in order to reduce as much as possible friction forces. The so measured contact forces can be considered neither reduced due to the belt opening force being reduce by the friction nor to be overestimated due to be belt locking in the overlap.

Both configurations with overlap on top and at bottom were tested and the troughability test as per [17] was performed.

Considering the belt in transversal direction to have uniform stiffness (This is not correct as the belt has

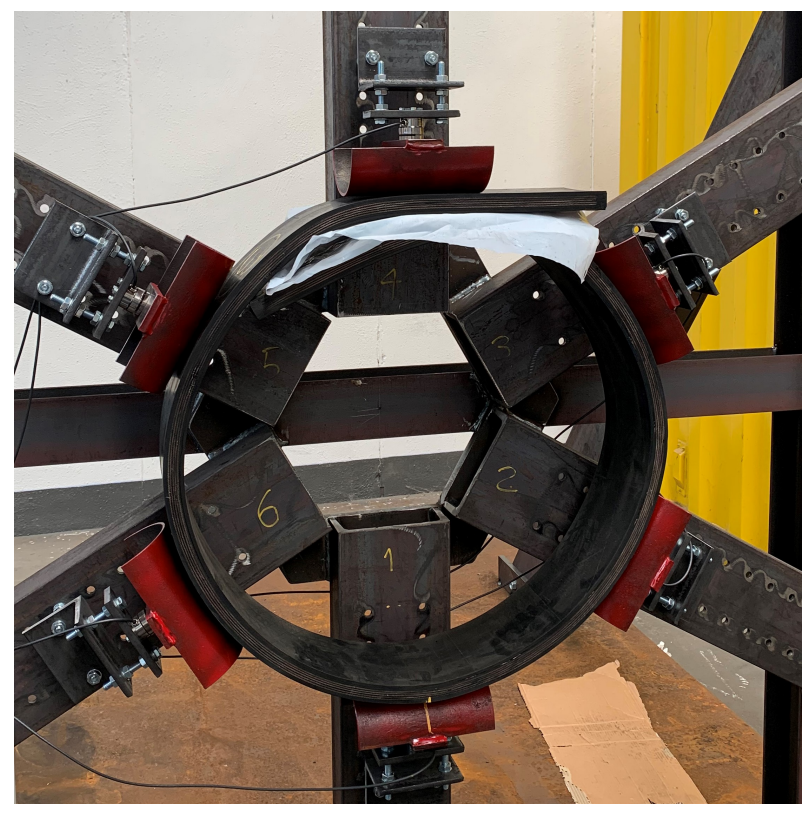

Figure 2: Six-point stiffness test device with sample installed in carrying strain configuration.

transversal steel reinforcement only in the central part and not extending out to the border.) the transversal stiffness can be estimated following the approach described in [20]. Using the analytical Fertis models results in a corresponding transversal stiffness of $45 \cdot 10^{6} \mathrm{~N} \mathrm{~m}^{-2} \mathrm{~m}^{-1}$.

\section{Material and methods}

Measurements on the pipe system had to be carried out during commissioning phase. This posed challenges not only on the measurement device as such but also on the installation onto the pipe system. Two locations along the pipe were identified, one in a straight section and one in the middle of the horizontal curve. The positions are indicatively shown in Figure 1. The two locations are on panel 145, located about $385 \mathrm{~m}$ from tail drum and on panel

Table 1: Results from the six-point stiffness test of the two $0.15 \mathrm{~m}$ wide belt samples. For every sample the sample's weight, troughability and the force on roller 01 to 12 is shown. Last two rows arithmetic mean and standard deviation of measured values.

\begin{tabular}{cccccccccccccccc}
\hline & \multicolumn{1}{c}{ Sample } & $\begin{array}{c}\text { Mass } \\
\mathrm{kg}\end{array}$ & $\begin{array}{c}y_{\max } \\
\mathrm{m}\end{array}$ & 01 & 02 & 03 & 04 & 05 & 06 & 07 & 08 & 09 & 10 & 11 & 12 \\
& 12.19 & 0.838 & 180 & 188 & 96 & 204 & 5 & 125 & 277 & 30 & 76 & 95 & 106 & 36 \\
1 & 11.97 & 0.830 & 167 & 191 & 83 & 178 & 22 & 131 & 276 & 58 & 94 & 77 & 113 & 69 \\
\hline$\mu$ & 12.08 & 0.834 & 173 & 189 & 89 & 191 & 14 & 128 & 277 & 44 & 85 & 86 & 109 & 52 \\
\hline$\mu$ & 0.16 & 0.006 & 9 & 2 & 9 & 18 & 12 & 4 & 1 & 20 & 12 & 13 & 5 & 23 \\
\hline
\end{tabular}




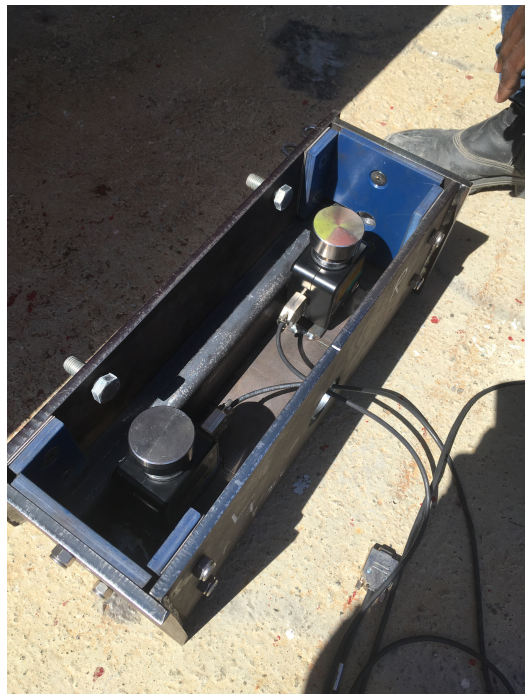

(a) View of the two digital dynamometers seen in the open special idler.

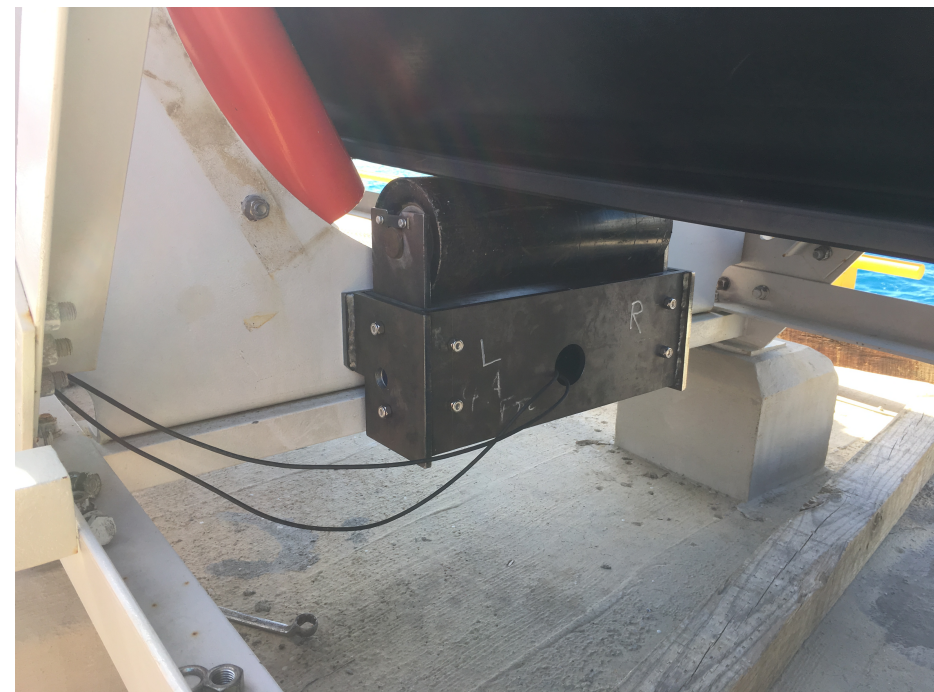

(b) Special idler installed in position 07 on panel 145.

Figure 3: Special idler constructed for measuring force excreted onto the roller.

711 located about $1555 \mathrm{~m}$ from tail. Panel 711 is in the horizontal curve's middle. Those location were chosen such to obtain representative data to directly compare with the laboratory experiments.

A special idler was constructed to measure forces excreted onto the rollers by the belt system, see Figure 3. This idler housed two digital dynamometers equipped with a spherical loading head on top. The roller support rests freely on top of the loading heads and any possible contact with the housing was reduced as much as possible. The digital dynamometer has a resolution of $5 \mathrm{~N}$ and the registered values can be logged via RS232C on a computer. The special idler housing was fixed with the same bolts to the panel as the standard idlers and care was taking to not alter roller the position.

In total measurements were taken in 22 roller positions on panel 145 and 711, not measuring roller in position 05 and 09 on panel 145. In each roller position the force of the left $F_{\text {left }}$ and right $F_{\text {right }}$ dynamometer was logged with a sample rate of $5 \mathrm{~Hz}$. The minimum measurement duration of each roller position was well beyond 900s. This is the time needed for the belt to complete one full revolution at a speed of $5.0 \mathrm{~ms}^{-1}$.

During most measurements, the absorption of the three motors and other drive related parameters were logged. Those data were used to verify the overall system behaviour during roller force measurement but are not discussed further.

\section{Field measurement results and discussion}

The raw data for every roller position needed preprocessing before undergoing specific analysis. Due to the inherent functionality of the RS232C interface the logs of the two dynamometers are not done at the same time instant. Performing any operations (e.g. $F_{\text {tot }}=F_{\text {left }}+F_{\text {right }}$ ) on the two signals $F_{\text {left }}$ and $F_{\text {right }}$ required to re-sample them to make the discrete values have identical time instants.

In the first part, the data are analysed in the time domain, performing auto-covariance and cross-covariance of the signals. As special cross-covariance is made between the signal and an identification function in order to identify individual sections of the belt. The study in the time domain is concluded with probability density of the force signals. In the second part, the deviation angle $\delta$ from the roller centre to the presumed contact point (see Figure 11) is derived and the data presented in radial graphs. A quick view on the probability density of the deviation angle concludes the study. The last and third part shows the results of forces on roller 01 on panel 145 while coal is conveyed. The section concludes with a table collecting the contact force values and comparing them to the experimentally obtained values. 


\subsection{Time domain analysis}

The individual signals were visually inspected for any anomalies. In this process the boundaries, start and end of measurement period, were set. Figure 4 show the left $F_{\text {left }}$ and right $F_{\text {right }}$ roller force data as well as the summed force $F_{t o t}$.

A further target was to identity the force $F_{\text {static }}$ acting on the rollers with the belt at rest. From looking at the signals it became clear that after the belt halted the roller force reached a constant value after about 10s. This constant value is taken as static roller force $F_{\text {static }}$. The static force $F_{\text {static }}$ for the various roller positions can be found in Table 2.

Looking at the signal in Figure 4 a not surprising repetitive pattern becomes visual. In addition, the signal shows distinct footprints i.e. offset of the mean for a certain duration. Detecting those regularities can reveal fundamental in context of computerized system identification and anomaly detection.

The arithmetic mean $\mu_{f}$ of a finite-duration sequences $f(i)$ with number of elements $N$ is defined as

$$
\mu_{f}=\frac{1}{N} \sum_{i=1}^{N} f(i)
$$

and the standard deviation $\sigma_{f}$ as

$$
\sigma_{f}=\sqrt{\frac{1}{N-1} \sum_{i=1}^{N}\left(f(i)-\mu_{f}\right)^{2}} .
$$

A powerful instrument to understand temporal similarity of two series is the cross-correlation. The cross-

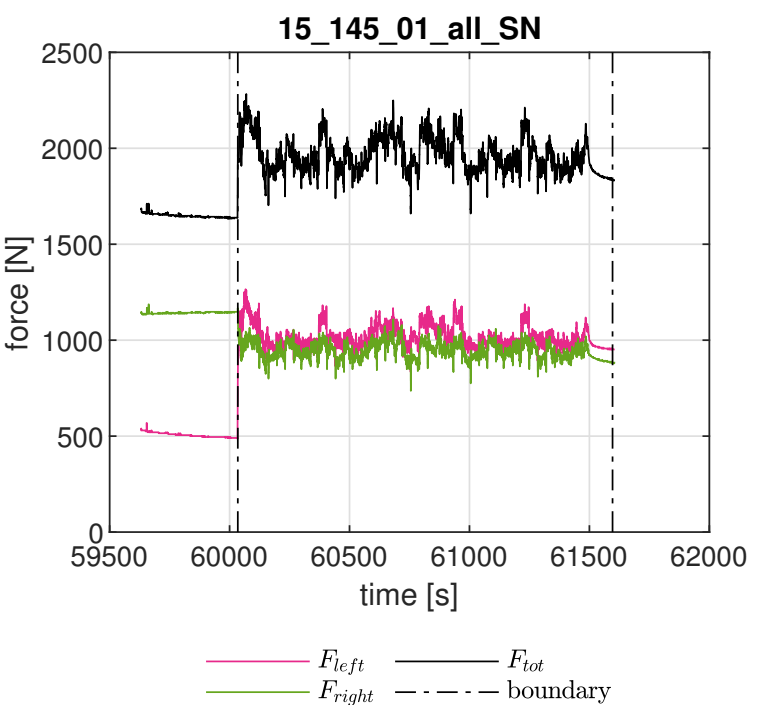

Figure 4: Left, right and summed force acting on roller 01 on panel 145. The boundary indicates start and end of measurement. correlation and autocorrelation (signal correlated with itself) for finite-duration sequences $x(n)$ and $y(n)$ can be expressed as

$$
\begin{aligned}
& c_{x y}(l)=\sum_{n=i}^{N-|k|-l}\left(x(n)-\mu_{x}\right)\left(y(n-l)-\mu_{y}\right) \\
& c_{x x}(l)=\sum_{n=i}^{N-|k|-l}\left(x(n)-\mu_{x}\right)\left(x(n-l)-\mu_{x}\right)
\end{aligned}
$$

where $i=l, k=0$ for $l \leq 0$, and $i=0, k=l$ for $l<0$ following [18], mean see Eq. (1). The cross-correlation can be normalised following

$$
\bar{c}_{x y}(l)=\frac{c_{x y}(l)}{\sqrt{c_{x x}(0) c_{y y}(0)}}
$$

and the autocorrelation can be normalised following

$$
\bar{c}_{x x}(l)=\frac{c_{x x}(l)}{c_{x x}(0)} .
$$

All temporal correlation studies are carried out on the summed roller force $F_{t o t}$. The above formulae are only valid when the signal is discrete in time with constant sampling rate. In consequence the time interval has no influence on the correlation. In the following, lag is number of discrete sample points, i.e. with a sampling frequency of $5 \mathrm{~Hz}, 1$ lag corresponds to $0.2 \mathrm{~s}$.

As the belt is a continuous loop, the expectation is the signal to repeat itself after the belt to complete one full revolution. Therefore, the autocorrelation should give the
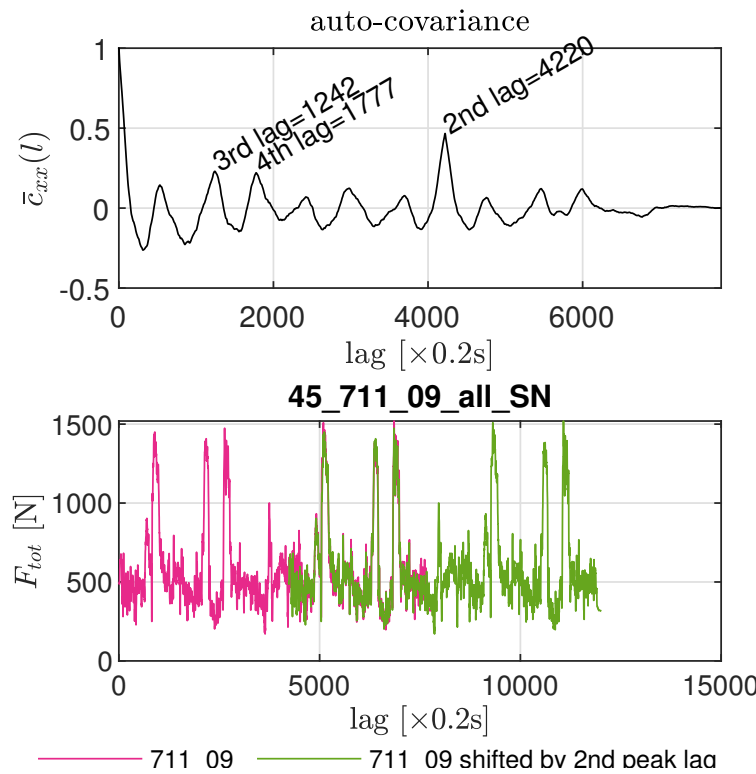

Figure 5: Upper plot normalised auto-correlation with 2nd to 4th peak identified. Bottom plot signal overlaid with shifted signal by 2nd peak's lag. Signal name indicated in the title of bottom plot. 
second highest correlation value exactly when the signal starts to repeat itself. in the upper part Figure 5 shows the autocorrelation function identifying 2nd to 4th peak, in the lower part the signal is overlaid with itself shifted for the lag of the second most significant peak.

Looking at the autocorrelation analysis of all signals shows the 2nd peak's lag to range from $4214 \times 0.2 \mathrm{~s}$ to $4232 \times 0.2 \mathrm{~s}$. With an effective belt speed of $5.18 \mathrm{~ms}^{-1}$ (the belt more likely runs at the speed of its external surface when wrap around a driving drum) the lag translate into a belt length of $4366 \mathrm{~m}$ to $4384 \mathrm{~m}$. This is well in line with the theoretical overall belt length of $4382 \mathrm{~m}$ leading to a maximum length error of $-0.3 \%$ in relation to the theoretical belt length.

The cross-correlation calculated between two different roller force measurements indicates of the degree of similarity. In Figure 6 this is done for the roller 04 and 07 on panel 145. Although, apparently the signals have low similarity the cross-correlation maximises with $\bar{c}_{x y}=0.645$.

The cross-correlation was calculated for multiple combination of roller positions. What comes apparent is that the cross-correlation value as such may not be very high however, the peaks are distinctive, see Figure 7.

When the cross-correlation is computed between a signal and a defined function (or template function), patterns on the signal can be identified. The aim here is to identify individual belt sections revealing themselves with an offset mean value. The template function $\tilde{F}(t)_{t m p}$ is defined
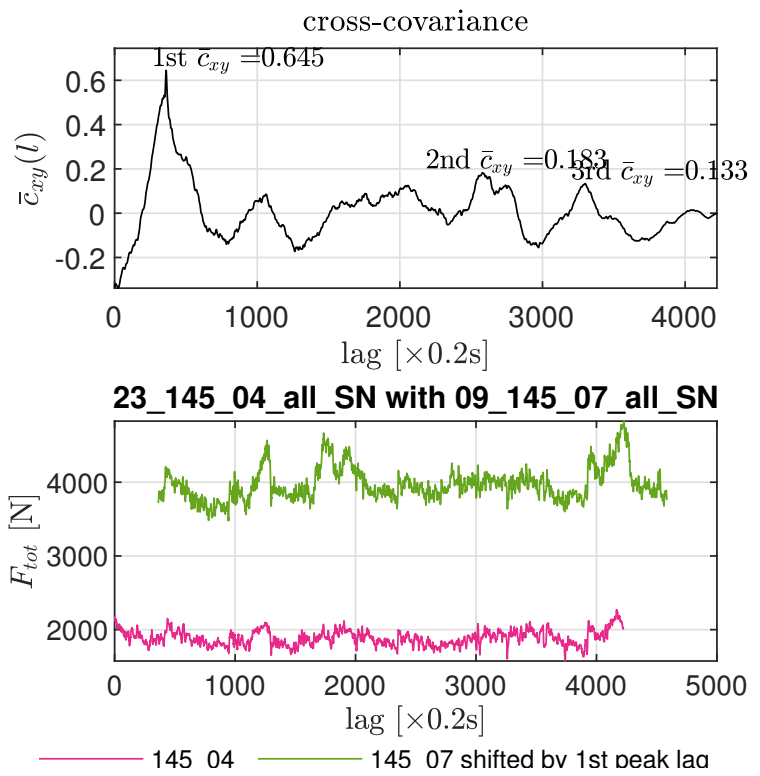

Figure 6: Upper plot normalised cross-correlation of loads on two different rollers indicating 1 st to 3 rd peak. Bottom plot signal overlaid with shifted signal by 1st peak's lag.

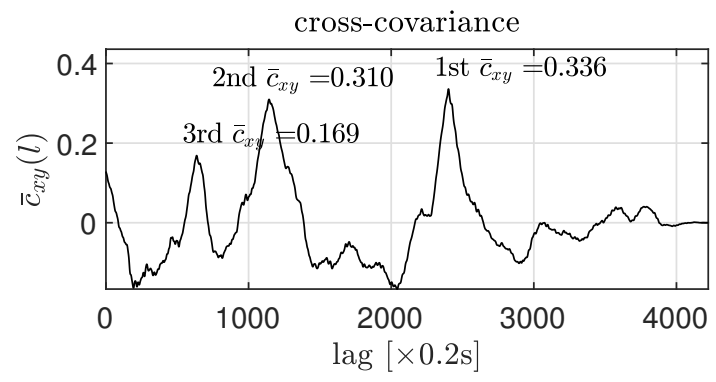

03_145_12_all_SY with $07 \_145 \_08 \_a l l \_S N$

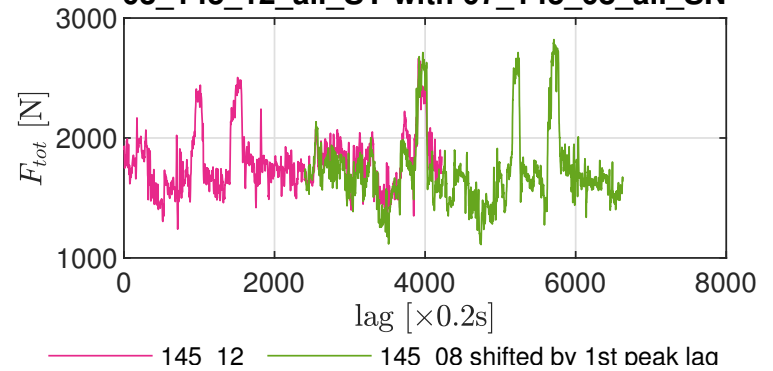

Figure 7: Upper plot normalised cross-correlation of loads on two different rollers indicating 1 st to 3 rd peak. Bottom plot signal overlaid with shifted signal by 1 st peak's lag.

as

$$
\tilde{F}(t)_{t m p}=F(t)_{t m p}-m_{F\left(t t_{t m p}\right.}= \begin{cases}F_{\text {const. }} & \text { if } 0 \leq t<t_{0} \\ \varepsilon & \text { if } t_{0} \leq t\end{cases}
$$

with $F_{\text {const. }}$ constant value, $\varepsilon$ a sufficient small number close to 0 . The belt section length $s$ is considered as its travel time $t_{0}=s / v$. Following values were applied
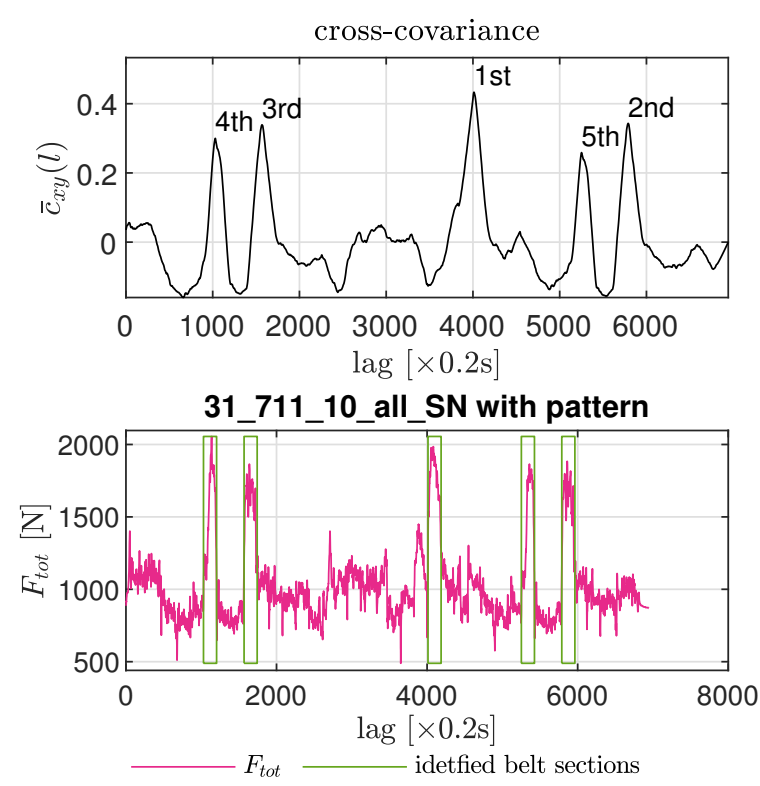

Figure 8: Upper plot normalised cross-correlation between roller force and template function indicating 1 st to 5 th peak. Bottom plot roller force signal with marked areas of identified belt section. 
Table 2: Compendium of measured force on rollers. Forces are scaled to a $1.0 \mathrm{~m}$ long belt element.

\begin{tabular}{|c|c|c|c|c|c|c|c|c|c|c|c|c|c|}
\hline \multirow[b]{2}{*}{ Value } & \multirow[b]{2}{*}{ Unit } & \multicolumn{12}{|c|}{ Roller } \\
\hline & & 01 & 02 & 03 & 04 & 05 & 06 & 07 & 08 & 09 & 10 & 11 & 12 \\
\hline & & \multicolumn{12}{|c|}{ Laboratory experiment } \\
\hline$\mu_{F_{e x p}}$ & $\mathrm{Nm}^{-1}$ & 1157 & 1261 & 594 & 1274 & 93 & 855 & 1844 & 295 & 565 & 575 & 728 & 349 \\
\hline \multirow{2}{*}{$\sigma_{F_{e x p}}$} & $\mathrm{Nm}^{-1}$ & 60.1 & 13.1 & 61.2 & 118.5 & 81.1 & 27.6 & 3.4 & 131.3 & 83.1 & 85.9 & 33.4 & 152.5 \\
\hline & & \multicolumn{12}{|c|}{ Field measurement on Panel 145} \\
\hline$\mu_{F_{\text {tot }}}$ & $\mathrm{Nm}^{-1}$ & 899 & 693 & 257 & 861 & - & 924 & 1803 & 768 & - & 439 & 640 & 814 \\
\hline$\sigma_{F_{t o t}}$ & $\mathrm{Nm}^{-1}$ & 42.7 & 34.5 & 50.3 & 53.3 & - & 46.8 & 103.5 & 112.3 & - & 132.4 & 125.2 & 102.7 \\
\hline$F_{\text {static }}$ & $\mathrm{Nm}^{-1}$ & 837 & 652 & 246 & 653 & - & 802 & 1494 & 664 & - & 333 & 411 & 667 \\
\hline$\mu_{\delta}$ & $\circ$ & 0.93 & -1.43 & 4.11 & -4.14 & - & -2.06 & 4.19 & 7.84 & - & -0.56 & 2.50 & -10.43 \\
\hline \multirow[t]{2}{*}{$\sigma_{\delta}$} & $\circ$ & 0.573 & 0.546 & 3.479 & 1.219 & - & 0.478 & 0.901 & 1.483 & - & 0.738 & 0.650 & 1.396 \\
\hline & & \multicolumn{12}{|c|}{ Field measurement on Panel 711} \\
\hline$\mu_{F_{t o t}}$ & $\mathrm{Nm}^{-1}$ & 1351 & 1421 & 1087 & 1062 & 156 & 666 & 1801 & 779 & 357 & 652 & 1186 & 1539 \\
\hline$\sigma_{F_{t o t}}$ & $\mathrm{Nm}^{-1}$ & 64.7 & 65.8 & 62.8 & 99.5 & 44.5 & 68.0 & 154.0 & 152.0 & 166.5 & 170.3 & 139.7 & 169.0 \\
\hline$F_{\text {static }}$ & $\mathrm{Nm}^{-1}$ & 1116 & 1040 & 749 & 562 & 203 & 499 & 1658 & 572 & 203 & 549 & 895 & 1450 \\
\hline$\mu_{\delta}$ & $\circ$ & -1.48 & -4.76 & 7.01 & -5.21 & 14.44 & 7.39 & 2.20 & 7.31 & 5.13 & -0.96 & -3.52 & -8.44 \\
\hline$\sigma_{\delta}$ & $\circ$ & 0.472 & 0.603 & 1.315 & 1.219 & 5.710 & 0.544 & 0.925 & 1.137 & 1.564 & 0.640 & 0.450 & 1.271 \\
\hline
\end{tabular}

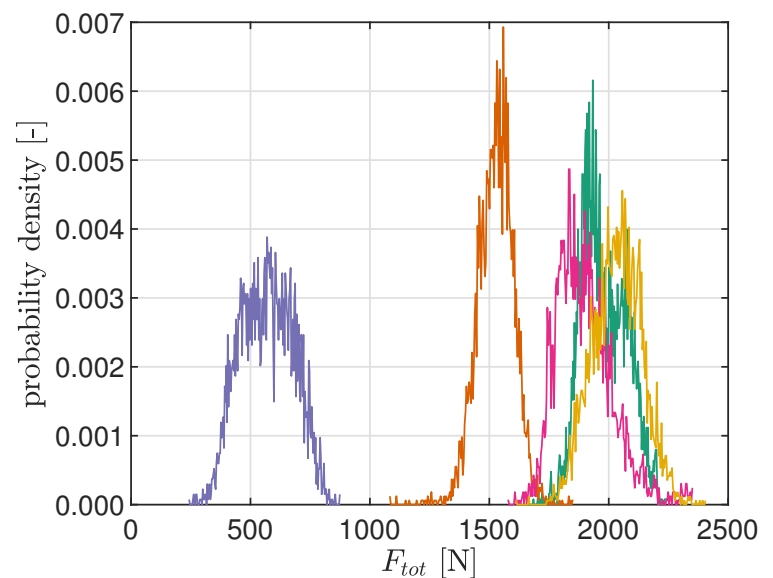

$\begin{array}{rr}-15 \_145 \_01 & \text { 19_145_02 } \\ -23 \_145 \_04 & \text { 27_145_06 }\end{array}$

Figure 9: Probability density of the force on the rollers on panel 145 carrying strain.

$F_{\text {const. }}=485 \mathrm{~N}, \varepsilon=-4.85 \mathrm{~N}$ and belt section length $s=$ $180 \mathrm{~m}$.

Figure 8 shows that in the 4223 lags long belt three distinct belt sections were identified. These three belt sections can be understood as to be stiffer in transversal direction and in consequence exerting higher forces on the roller.

The probability density for the force acting on the carrying strand rollers are shown in Figure 9 and Figure 10. Together with the probability density the mean $\mu_{\text {meas }}$ and standard deviation $\sigma_{\text {meas }}$ of the force is computed, see Ta-

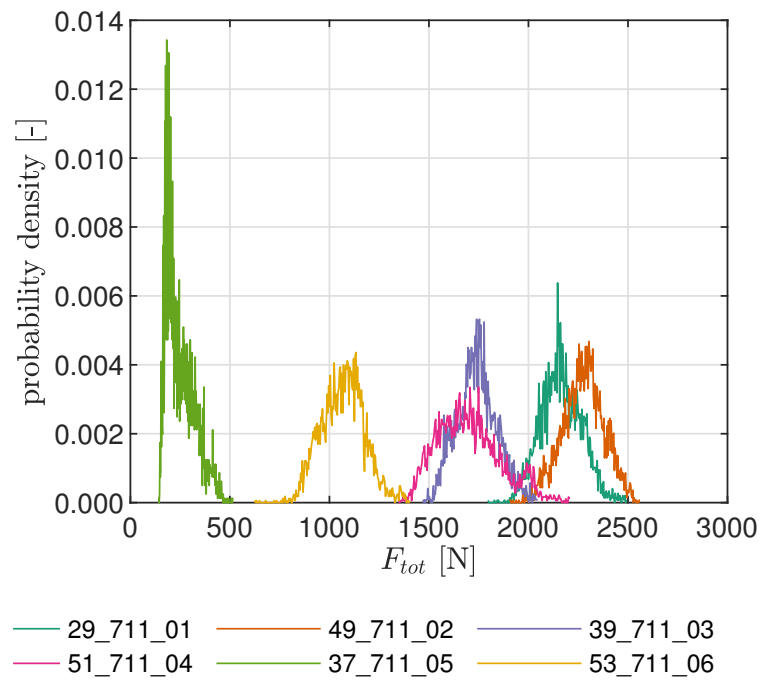

Figure 10: Probability density of the force on the rollers on panel 711 carrying strain.

ble 2 . The plots and values are derived taking one complete revolution of the belt.

The first thing, coming apparent comparing Figure 9 and Figure 10 is the shift of the force on rollers on panel 711. As expected, roller 02 and 03 located towards the centre of the horizontal curve increase whereas roller 05 and 06 decrease. The top and bottom rollers 01 and 04 do not change significantly.

Assuming the force on the roller to be a uniform stochastic process, the force distributions should be normally distributed. However, a certain level of divergence 
can be observed. Among others, this can be attributed to the non-uniformity of the individual belt sections.

\subsection{Radial representation}

An interesting parameter to investigate is the theoretical contact points of the belt on the rollers. The contact point location for every roller can be estimated based on the two (left and right) dynamometer readings. The deviation angle $\delta$ between the roller centre and the contact point is defined as graphed in Figure 11 and expressed in Eq. (8).

$$
\sin \delta=\frac{\Delta L}{R}\left(\frac{1}{2}-\frac{F_{\text {right }}}{F_{\text {left }}+F_{\text {right }}}\right),
$$

with $\Delta L$ axial distance of the load cells $300 \mathrm{~mm}$, and $R$ external radii of pipe $350 \mathrm{~mm}$. The measurement idler was always installed such that the left dynamometer is in anticlockwise position of the right one.

Figure 12,13,14 and 15 show the force on the roller for all measured roller positions on panel 145 and 711. It can be observed that the mean deviation angle is never $0^{\circ}$ and thus the contact points is not in the roller centre. Worth noticing is that, the contact point on rollers left and right from the overlap move towards it. This independent if the panel is located in a horizontal curve or not.

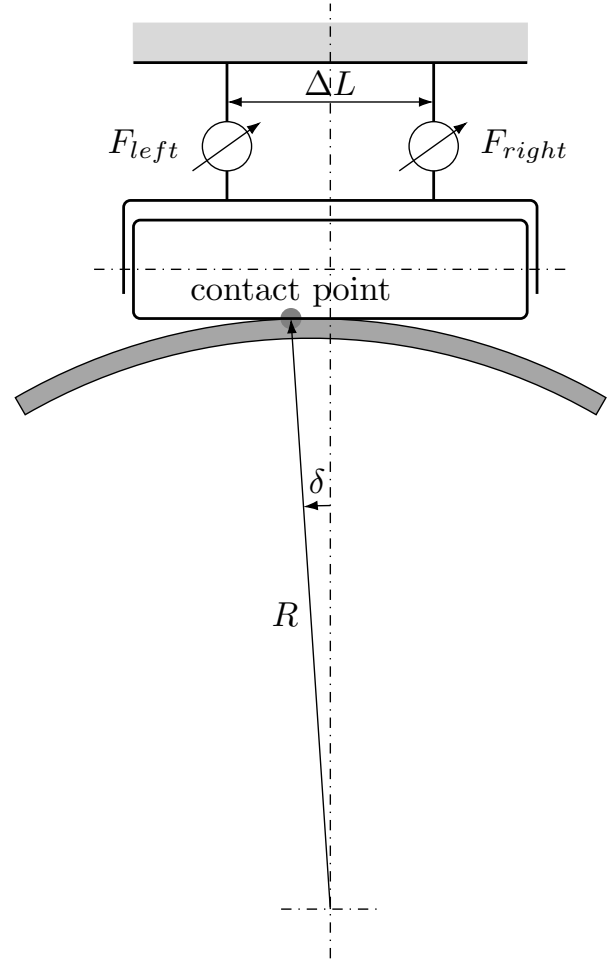

Figure 11: Definition of the deviation angle $\delta$ between the roller centre and the theoretical contact point.
The probability density distribution of the deviation angle $\delta$ is shown in Figure 16. The mean $\mu_{\delta}$ and standard deviation $\sigma_{\delta}$ of the deviation angle $\delta$ is listed in Table 2.

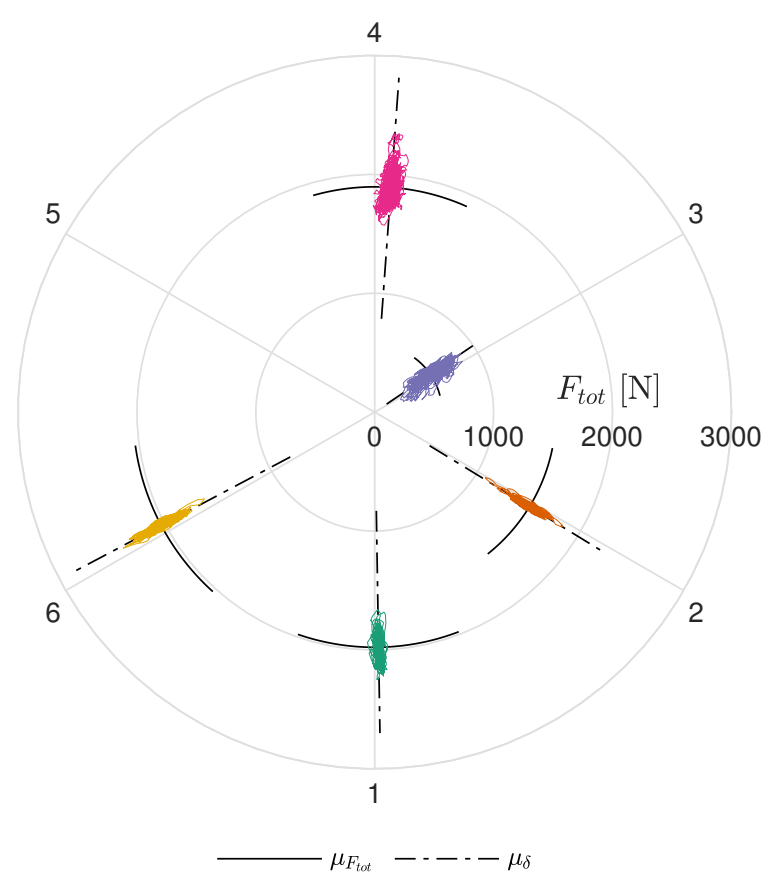

Figure 12: Plot showing forces $F_{\text {tot }}$ on panel 145 carrying strain rollers, together with the mean force $\mu_{F_{t o t}}$ and mean angle $\mu_{\delta}$ are shown.

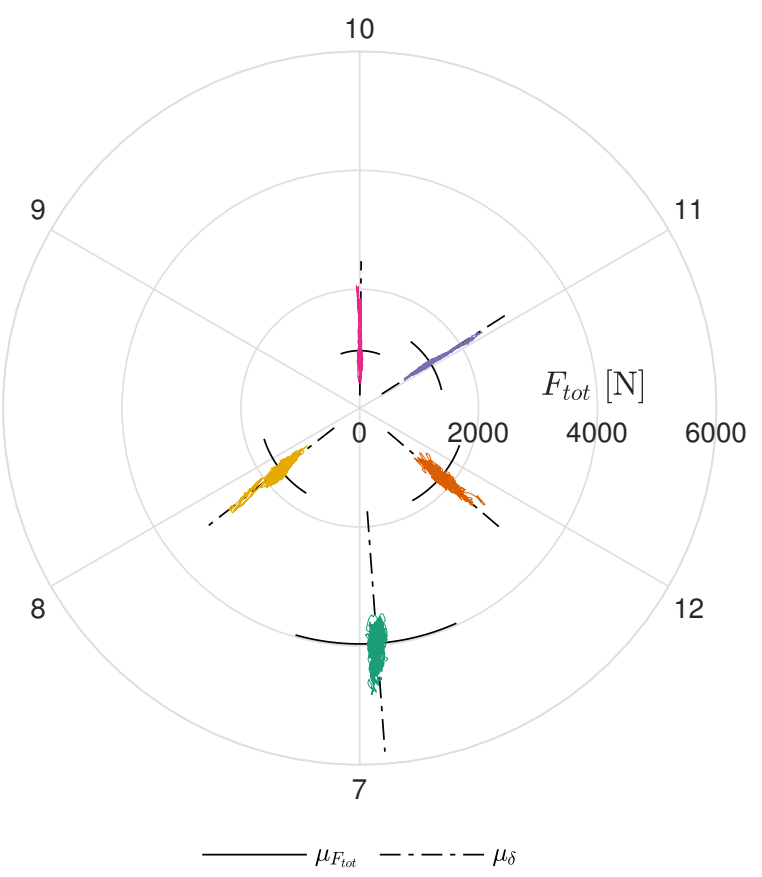

Figure 13: Plot showing forces $F_{\text {tot }}$ on panel 145 carrying return rollers, together with the mean force $\mu_{F_{t o t}}$ and mean angle $\mu_{\delta}$ are shown. 


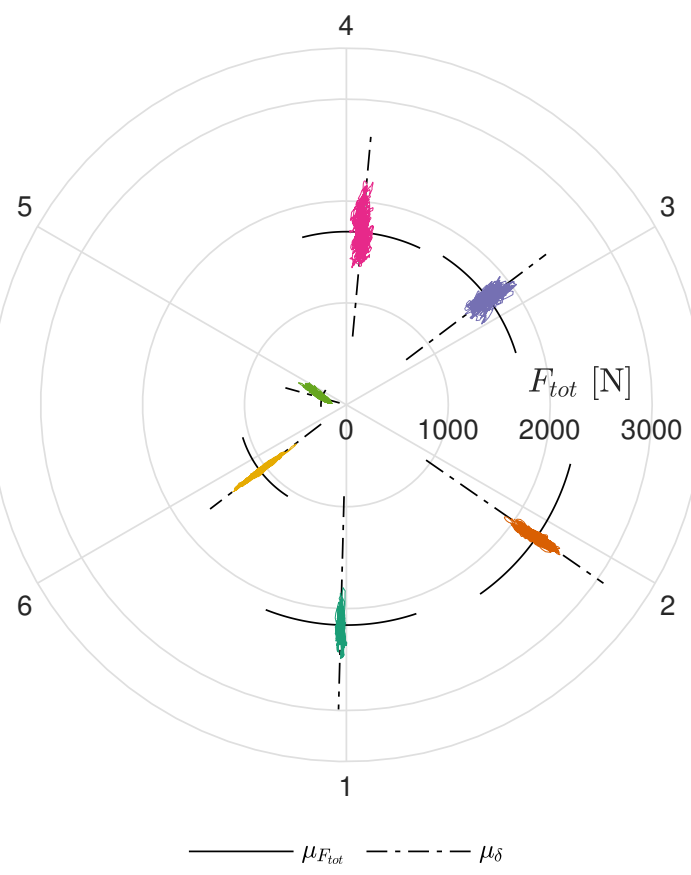

Figure 14: Plot showing forces $F_{\text {tot }}$ on panel 711 carrying strain rollers, together with the mean force $\mu_{F_{t o t}}$ and mean angle $\mu_{\delta}$ are shown.

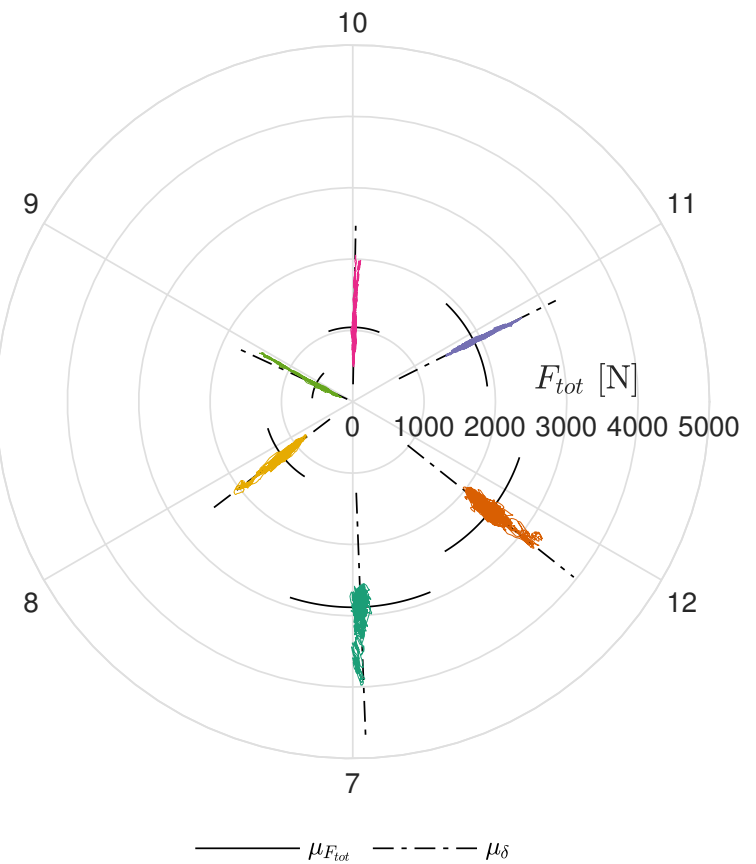

Figure 15: Plot showing forces $F_{\text {tot }}$ on panel 711 return strain rollers, together with the mean force $\mu_{F_{t o t}}$ and mean angle $\mu_{\delta}$ are shown.

\subsection{Force on roller while conveying}

Commissioning phase foresaw several conveying material tests. During such test the forces $L_{\text {left }}$ and $L_{\text {right }}$ acting on roller 01 on panel 145 were measured. To differentiate from

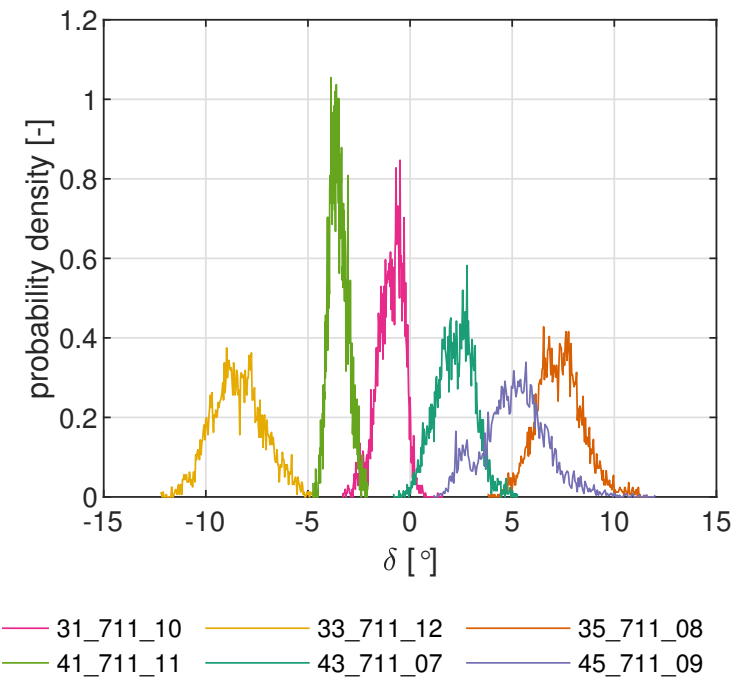

Figure 16: Probability density of deviation angle $\delta$ on panel 711 return strain rollers.

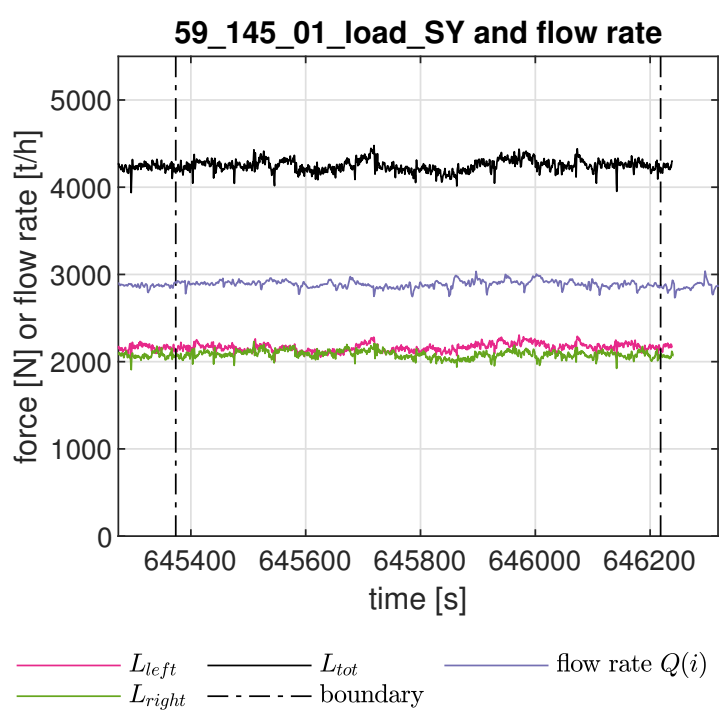

Figure 17: Left, right and summed force acting on roller 01 on panel 145 while conveying material. On the same axis the instantaneous material flow rate is plotted. The boundary indicates one complete belt length.

forces on roller denominated with $F_{\text {... measured without }}$ conveying material. For the sake of clarity when material is conveyed the forces are denominated with $L_{\ldots}$. The measurements were carried out in two occasions with measurement duration larger than one hour. Figure 17 shows the measured forces together with the instantaneous material flow rate $Q(i)$.

The roller forces with and without conveying material can be set in following relation

$$
F_{t o t, n}=L_{t o t, n}-W_{\text {mat }} \varphi_{n},
$$




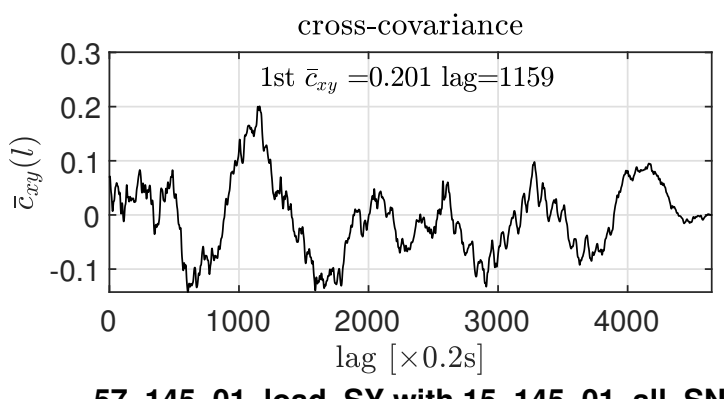

5714501 load SY with 1514501 all SN

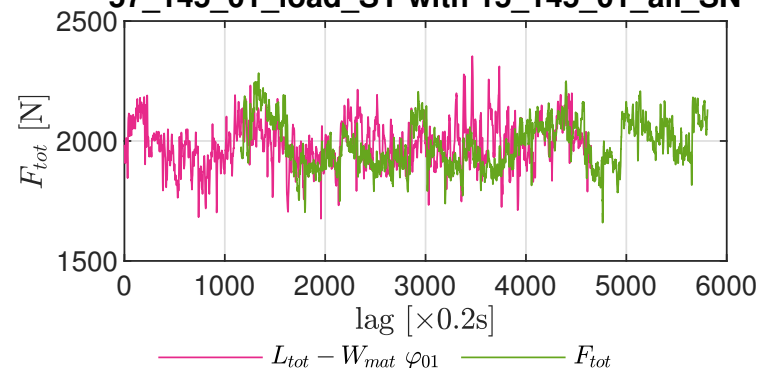

Figure 18: First example: Cross-correlation of measured force on roller with and without material being conveyed. In the bottom plot signal overlaid with shifted signal by 1st peak's lag.
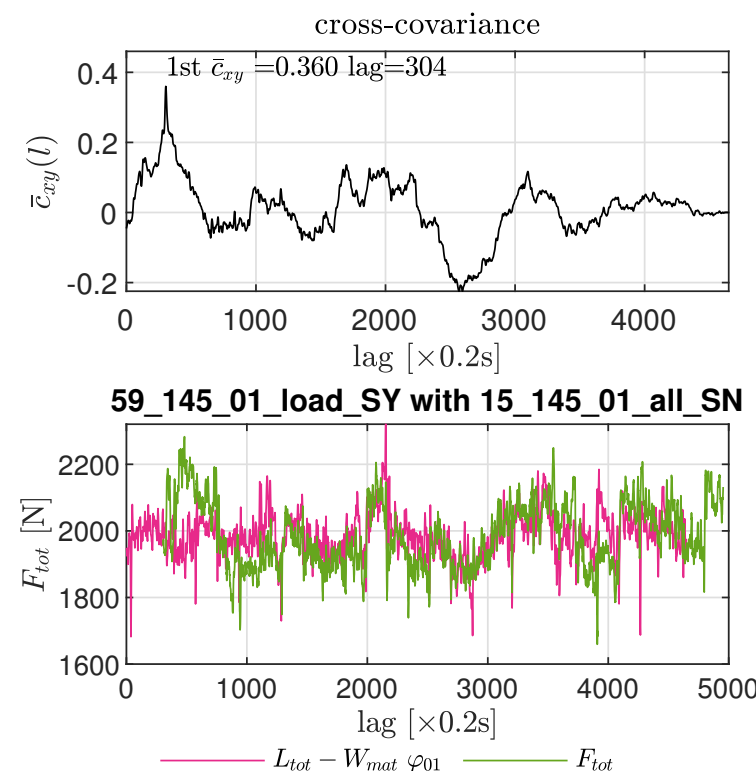

Figure 19: Second example: Cross-correlation of measured force on roller with and without material being conveyed. In the bottom plot signal overlaid with shifted signal by 1st peak's lag.

with $W_{\text {mat }}$ material weight and $\varphi_{n}$ participation factor of material load on force on roller $n$. The material weight $W_{\text {mat }}$ can be derived from the instantaneous material flow rate $Q(i)$.

$$
W_{\text {mat }}=\frac{Q(i)}{v} l
$$

with $Q(i)$ instantaneous material flow rate, $v=5.18 \mathrm{~ms}^{-1}$ and $l=2.2 \mathrm{~m}$ panel spacing. Here, the instantaneous material flow rate $Q(i)$ is indicated as a function of $(i)$ to underline it being a non-constant finite-duration sequences.

On the conventional conveyor belt feeding the pipe, a weight scale is installed metering the instantaneous material flow rate $Q(i)$. The instantaneous material flow rate $Q(i)$ gauged at the scale reaches panel 145 approximately 84.8 s later. For the analysis $Q(i)$ was shifted accordingly in time.

Finally, the participation factor $\varphi_{n}$ of material load on force on roller $n$ can be expressed as

$$
\varphi_{n}=\frac{\mu_{L_{t o t, n}}-\mu_{F_{t o t, n}}}{\mu_{W_{\text {mat }}}}
$$

with arithmetic mean $\mu_{\text {... }}$ taken over one belt length. From the data analysis a participation factor $\varphi_{01}=0.68$ results. Similar, although slightly smaller value was found by [14]. For conventional belt conveyors with trough angle of $60^{\circ}$ the participation factor $\varphi_{n}$ is slightly larger, see [19].

Figure 18 and 19 show two examples of the crosscorrelation of the measured force on roller with and without material being conveyed. For both examples good cross-correlation is achieved and the $L_{t o t}-W_{m a t} \varphi_{01}$ signal has the same distinctive patter as $F_{t o t}$. The lag is not the same in both examples as the pipe conveyor was halted and restarted in-between.

\subsection{Data compendium}

Table 2 collects the data from laboratory experiment and field measurements. The values are stated for a $1 \mathrm{~m}$ long belt segment. Following scale factors apply, $1 / 0.15 \mathrm{~m}$ for laboratory experiment, $1 / 2.2 \mathrm{~m}$ on panel 145 and $1 / 1.6 \mathrm{~m}$ on panel 711.

To evaluate the exactness of the measurements the sum of vertical forces (including belt mass) and the sum of horizontal forces is related to the total sum of roller forces. In perfect condition this ratio would result zero. For the laboratory experiments the vertical force ratio is 0.036 and the horizontal ratio 0.097. During the field measurements only on panel 711 all 6 rollers where measured. The vertical force ratio is 0.067 and the horizontal force ratio 0.122 . When making the sum of horizontal forces the estimated horizontal radial force due to belt tension was considered. The ratios result sufficient small to proof the values trustworthy.

In general terms it becomes apparent that the field measurements for panel 145 and 711 are well aligned. For both panel and on the carrying and return strain, the most 
loaded roller (apart from belt and material mass) is the one where the overlap rests, rollers 04 and 07 . The laboratory experiment compared to panel 145 , give values indicatively in line. However, the laboratory values are not sufficiently exact to base the roller design on. Computing $F_{\text {static }}$ ratio $\mu_{F_{t o t}}$ shows that the static force can be as low as $53 \%$ of $\mu_{F_{\text {tot }}}$.

\section{Conclusion}

The forces acting on pipe conveyor rollers were assessed with a special idler mounted in different roller and panel position while and while not conveying material. These data were analysed in the time domain and the theoretical contact point calculated. Main stochastic parameters of the force acting onto the rollers are derived and the system identified with help of cross-correlation.

During these analyses it could be shown that a system identification can be performed on the force signals. Especially, individual belt section could be clearly identified, proofing the general non uniformity of the belt in terms of transversal stiffness.

One cardinal point is the belt tension [4], which has an important role in the roller forces. This manifest the large difference between static force and force acting while the conveyor is running on the rollers. An important factor which must be considered when dealing with high tensional force in belt are installation tolerances. Which, as small as they may be, by deviating the belt increase the force acting on the rollers significantly.

Comparing forces on rollers whilst conveying material with forces without conveying material allows to derive the material load participation factor for every roller. For the roller in central bottom position is results in $\varphi_{01}=0.68$.

To further enhance the presented method, it would be necessary to make a permanent installation and measure simultaneously the forces on all rollers. Combined with an evaluation unit it would allow for a continuous system monitoring. To increasingly fine tune the overall system characterisation the horizontal roller force component and the belt tension should be included into the analysis.

Finally, the measured values are compared with those obtained from a six-point stiffness test. This test allows to gain insight into the behaviour of the belt and contact forces. However, they are not sufficient representative to base design decisions on. In the laboratory the friction in the overlap is reduced as much as possible, however its possible impact especially in the field is not sufficiently considered.
Based on this study it becomes immanent that, there is limited knowledge when it comes to the design of large diameter pipe conveyors. The lack of a sound analytical model and or experimental setup to estimate the contact forces make a reliable design difficult and specially to perform an economic design nearly impossible. The data here presented however, give a solid reference in terms of force magnitude and distribution for pipe conveyor systems utilizing belts with similar transversal stiffness and width.

\section{Declaration of Competing Interest}

The authors declare that they have no known competing financial interests or personal relationships that could have appeared to influence the work reported in this paper. Further, this research did not receive any specific grant from funding agencies in the public, commercial, or not-forprofit sectors.

\section{Data Availability Statement}

Some or all data, models, or code generated or used during the study are proprietary or confidential in nature and may only be provided with restrictions. The system description, drawings and photos are restricted. The measured data that support the findings of this study are available from the corresponding author, [E.B.], upon reasonable request. The data analysis code is shared under AttributionNonCommercial 4.0 International (CC BY-NC 4.0).

\section{References}

[1] M. Zamiralova, G. Lodewijks, Pipe conveyor test rigs: Design, application and test results - part a, Bulk Solids Handling 34 (5) (2014) 40-45.

[2] V. Molnár, G. Fedorko, M. Andrejiová, A. Grinčová, M. Kopas, Monitoring of dependences and ratios of normal contact forces on hexagonal idler housings of the pipe conveyor, Measurement 64 (2015) 168-176. http://dx.doi.org/10.1016/j. measurement.2014.12.055.

[3] V. Molnár, G. Fedorko, B. Stehlíková, L. Kudelás, N. Husáková, Statistical approach for evaluation of pipe conveyor's belt contact forces on guide idlers, Measurement 46 (9) (2013) 3127-3135. http://dx.doi.org/10.1016/j.measurement.2013.06.019.

[4] V. Molnár, G. Fedorko, B. Stehlíková, P. Michalik, M. Kopas, Mathematical models for indirect measurement of contact forces in hexagonal idler housing of pipe conveyor, Measure- 
ment 47 (2014) 794-803. http://dx.doi.org/10.1016/j.measurem ent.2013.10.012.

[5] V. Molnár, G. Fedorko, M. Andrejiová, A. Grinčová, P. Michalik, Online monitoring of a pipe conveyor. part i: Measurement and analysis of selected operational parameters, Measurement 94 (2016) 364-371.

[6] V. Molnár, G. Fedorko, M. Andrejiová, A. Grinčová, P. Michalik, Online monitoring of pipe conveyors part II: Evaluation of selected operational parameters for the design of expert system, Measurement 104 (2017) 1-11.

[7] V. Molnár, G. Fedorko, L. Homolka, P. Michalik, Z. Tučková, Utilisation of measurements to predict the relationship between contact forces on the pipe conveyor idler rollers and the tension force of the conveyor belt, Measurement 136 (2019) 735-744.

[8] V. Molnár, G. Fedorko, S. Honus, M. Andrejiová, A. Grinčová, P. Michalik, Prediction of contact forces on idler rolls of a pipe conveyor idler housing for the needs of its online monitoring, Measurement 139 (2019) 177-184.

[9] M. Zamiralova, G. Lodewijks, Measurement of a pipe belt conveyor contact forces and cross section deformation by means of the six-point pipe belt stiffness testing device, Measurement 70 (2015) 232-246.

[10] M. Zamiralova, G. Lodewijks, Pipe conveyor test rigs: Design, application and test results - part b, Bulk Solids Handling 34 (6) (2014) 38-46.

[11] M. Zamiralova, G. Lodewijks, Pipe conveyor test rigs: Design, application and test results - part c, Bulk Solids Handling 35 (1) (2015) 42-49.
[12] M. Barburski, Analysis of the pipe conveyor belt pressure on the rollers on its circuit., Journal of Industrial Textiles 45 (6) (2016) 1619-1634.

[13] Y. cun Guo, S. Wang, K. Hu, D. yong Li, Optimization and experimental study of transport section lateral pressure of pipe belt conveyor, Advanced Powder Technology 27 (4) (2016) 1318-1324.

[14] Q. Zheng, M. Xu, K. Chu, R. Pan, A. Yu, A coupled FEM/DEM model for pipe conveyor systems: Analysis of the contact forces on belt, Powder Technology 314 (2017) 480-489.

[15] T. Bahke, Calculation criteria and application of "rollgurt" - conveyor (tube conveyor), in: BELTCON 6: International Materials Handling Conference (IMHC), South Africa, Johannesburg, 1991.

[16] S. Hötte, Experimentelle Untersuchungen zu den Normalkräften bei Schlauchgurten, no. ITA 03/2014, PZH Verl., TEWISS - Technik und Wissen, Garbsen, 2014.

[17] ISO 703:2007, Conveyor Belts - Transverse Flexibility (Troughability) - Test Method, International Standard ISO, 2007.

[18] J. G. Proakis, D. G. Manolakis, Digital signal processing: Principles, Algorithms, and Applications, third edition Edition, Prentice Hall, 1996.

[19] K. J. G. K. Grabner, F. Kessler, Research into normal-forces between belt and idlers at critical locations on the belt conveyor track, Bulk Solids Handling 13 (4) (1993) 727-734.

[20] M. Zamiralova, G. Lodewijks, Review of the troughability test ISO 703 for quantifying a uniform transverse bending stiffness for conveyor belts, Archives of Civil and Mechanical Engineering 17 (2017) 249-270. 